\title{
Новый сорт озимой белокочанной капусты Елизавета
}

\author{
Elizaveta, a new winter white cabbage cultivar
}

\section{Казахмедов Р.Э., Кафарова Н.М.}

\section{Аннотация}

Сорт, выведенный в определенных почвенно- климатических условиях, наиболее адаптирован к ним и в большей степени отвечает требованиям данного региона по качеству продукции. В этом случае селекция наиболее эффективна. Наша задача - объединить в одном сорте возможно большее число хозяйственно ценных признаков: высокая урожайность, скороспелость, товарного качества продукции, устойчивость к болезням и вредителям (фузариозному увяданию, ложной мучнистой росе, листогрызущим гусеницам, тле). Но наиболее важный признак для возделывания капусты на юге страны - высокая жаростойкость. Поэтому в качестве одного из родителей, чаще материнской формы, обязательно используется местный сорт, хорошо приспособленный к местным условиям. В качестве отцовских форм, выполняющих роль доноров, привлекают образцы из других районов, ценные по тем или иным хозяйственным признакам. Для выделения новых адаптивных генотипов капусты белокочанной разных сроков созревания, в 2009-2014 годах, проводили дальнейшее сравнительное изучение и конкурсное испытание четырех гибридных форм и шести контрольных сортов в коллекции капусты белокочанной озимой станции. Материалом исследования в данной работе служили сорта, выведенные на дСОСВиО - сорт капусты белокочанной озимой Дербентская местная улучшенная (ДМУ), сортотип Бычье сердце, кочан конусовидный (стандарт), сорт Офелия (контроль) и новый сорт, под условным рабочим названием Лиза - сорт Елизавета, выведенный селекционером ДСОСВиО Камиловой Е.У. в 2008 году. Сорт Елизавета прошел конкурсное испытание в 2009-2014 годах на коллекционном участке станции. В данной работе представлены экспериментальные данные дополнительного сравнительного изучения сорта Елизавета в озимой культуре за 2017-2019 годы в изменяющихся климатических условиях на коллекционном участке Дагестанской селекционной опытной станции виноградарства и овощеводства (ДСОСВиО). Почвы - светло-каштановые. Подвижных форм азота в ней содержится 4,2-5,6 мг, фосфора (фосфата) - 6,2-8,6 мг, обменного калия - 45-50 мг на 100 г почвы. Мощность пахотного слоя - 30-35 см, окультуренность почвы хорошая. Схема посадки $70 \times 30$ см. Статья содержит агробиологическую и хозяйственно-технологическую характеристики перспективного сорта капусты белокочанной озимой селекции Дагестанской селекционной опытной станции виноградарства и овощеводства, а также основные элементы агротехники его возделывания в сухих субтропиках южного Дагестана. Новый сорт капусты белокочанной озимой превосходит по ряду хозяйственно ценных признаков контрольные сорта ДМУ и Офелия, при этом обладает большей устойчивостью к биотическим и абиотическим стрессорам. Сорт Елизавета будет передан в ГСИ в 2020 году и рекомендуется для внедрения в производство не только в Дагестане, но и во всех южных регионах России.

Ключевые слова: капуста белокочанная, селекция, сорт, озимая культура, скороспелость, урожайность, товарный урожай.

Для цитирования: Казахметов Р.Э., Кафарова Н.М. Новый сорт озимой белокочанной капусты Елизавета // Картофель и овощи 2020. №4. C. 37-40. https: //doi.org/10.25630/PAV.2020.32.70.007

\section{Kazakhmedov R.E., Kafarova N.M.}

\section{Abstract}

The cultivar bred in specific soil and climatic conditions is most adapted to them and meets the requirements of the region in terms of product quality. In this case, the breeding is most effective. Our task is to combine in one cultivar the largest possible number of economically valuable features: high yield, precocity, product quality, resistance to diseases and pests (Fusarium wilting, downy mildew, leaf-eating caterpillars, aphids). But the primary sign for growing cabbage in the South of the country is high heat resistance. Therefore, it is obligatory to use a local cultivar that is well adapted to local conditions as one of the parents, more often the mother form. As paternal cultivar that performs the role of donors, non-district samples are attracted, valuable for certain economic characteristics. In order to identify new adaptive genotypes of white cabbage of different maturation periods, in 2009-2014, a further comparative study and competitive testing of 4 hybrid forms and 6 control varieties in the collection of white cabbage of the winter station was carried out. Cultivars in the research work used were developed at Dagestan Selection and Experimental Station for Viticulture and Vegetable Growing (DSESVVG). There were winter white cabbage Derbentskaya mestnaya uluchshennaya, Bychye Serdtse (Bull heart) type, with conical head (standard), Ophelia cultivar (control) and a new cultivar, under the provisional working title Lisa - Elizabeth, bred by the breeder of DESVVG E.U. Kamilova in 2008. The Elizabeth cultivar passed a competitive test in 20092014 at the station's collection site. The article presents experimental data of an additional comparative study of the Elizaveta cultivar in winter culture for 2017-2019 in changing climatic conditions at the collection site of the DESVVG. The soils are light brown. It contains $4,2-5,6 \mathrm{mg}$ of mobile forms of nitrogen, $6,2-8,6 \mathrm{mg}$ of phosphorus (phosphate), and $45-50 \mathrm{mg}$ of exchange potassium per $100 \mathrm{~g}$ of soil. The capacity of the arable layer is $30-35 \mathrm{~cm}$, the soil is developed. Planting scheme $70 \times 30 \mathrm{~cm}$. The article contains agrobiological and economic-technological characteristics of promising cultivars of winter white cabbage bred at DESVVG as well as the basic elements of agrotechnology of its growing in the dry subtropics of southern Dagestan. The new cultivar of winter white cabbage surpasses the control cultivars in a number of valuable economic characteristics, while it has greater resistance to biotic and abiotic stressors. The Elizaveta variety will be transferred to the State cultivars testing in 2020 and is recommended for introduction into field growing not only in Dagestan, but also in all southern regions of Russia.

Key words: white cabbage, selection, variety, winter crop, precocity, yield, commodity crop.

For citing: Kazakhmetov R.E., Kafarova N.M. Elizaveta, a new winter white cabbage cultivar. Potato and vegetables. 2020. No4. Pp. 37-40. https: //doi.org/10.25630/PAV.2020.32.70.007 (In Russ.) 
$\mathrm{C}$ отрудники Дагестанской селекционной опытной станции виноградарства и овощеводства ведут многолетнюю плодотворную работу по селекции, сортоизучению и сохранению генетических ресурсов капусты белокочанной озимой. Рано весной спрос на раннюю капусту достаточно высок не только на Северном Кавказе, но и по всей России [1]. Если механизировать самую трудоемкую операцию - уборку, можно значительно повысить эффективность производства ранней капусты. Оптимальные сроки посева семян капусты белокочанной озимой в Дербентском районе - 10-15 сентября. Капуста - холодостойкое растение. Закаленная рассада выдерживает заморозки до $-7^{\circ} \mathrm{C}$, а в растения в фазе технической спелости и более низкие температуры. Семена начинают прорастать при 2-3 ${ }^{\circ} \mathrm{C}$, а оптимальная температура для роста и развития растений $-15-18^{\circ} \mathrm{C}$

Обычно в Дербенте с середины июня и до конца июля свежая капуста на рынок не поступала. Чтобы восполнить этот пробел, селекционеры поставили задачу - вывести новые озимые сорта белокочанной капусты, более ранние и урожайные, чем сорт Дербентская озимая улучшенная. Такие сорта уже созданы, часть из них прошла производственные испытания. В реестр селекционных достижений РФ вошли сорта Дербентская местная улучшенная (ДМУ), Самур 2, Горянка 5, Офелия, Лезгинка.

Цель исследований - создать новые высокоурожайные сорта капусты озимой белокочанной разных сроков созревания, устойчивые к болезням и вредителям, пригодные для механизированной уборки.

Условия, материалы и методы исследований

Станция расположена в черте города Дербент на 17 м ниже уровня моря. Климат здесь характеризуется мягкой непродолжительной зимой, прохладной затяжной весной, сухим и жарким летом, теплой и влажной осенью.

Материалом исследования служили сорта, выведенные на ДСОСВиО - сорт капусты белокочанной озимой Дербентская местная улучшенная (ДМУ), сортотип Бычье сердце, кочан конусовидный (стандарт), сорт Офелия (контроль) и новый сорт, под условным рабочим названием Лиза -сорт Елизавета выведенный селекционером ДСОСВиО Камиловой Е, У, в 2008 году. Сорт Елизавета прошел конкурсное испытание в 2009-2014 годах на коллекционном участке станции. В данной работе представлены экспериментальные данные дополнительного сравнительного изучения сорта в озимой культуре за 2017-2019 годы.

Краткая характеристика погодных условий в годы исследований: сентябрь 2018 года, время посева семян капусты озимой в холодные рассадники, был теплым. Среднемесячная температура воздуха $20{ }^{\circ} \mathrm{C}$. За этот период месячные сумма осадков 54 мм. Ноябрь 2018 года был также теплым. Средняя месячная температура воздуха- 9,6 ${ }^{\circ} \mathrm{C}$, сумма осадков 108,3 мм. Умеренно прохладная погода благоприятно отразилась на посадки капусты белокочанной озимой. Среднесуточная температура за январь 2019 года составило $4,7^{\circ} \mathrm{C}$, максимальная $11,9{ }^{\circ} \mathrm{C}$, минимальная $-1,1^{\circ} \mathrm{C}$. Осадков выпадало -15,4 мм. Относительная вланость воздуха 79\%. Среднесуточная температура в феврале была выше среднемноголетней на $2,3{ }^{\circ} \mathrm{C}$. Максимальный $12,5{ }^{\circ} \mathrm{C}$, минимальный $-2,3{ }^{\circ} \mathrm{C}$. Выпадение осадков 21,8 мм. В марте 2019 года отмечено резкие колебания температуры воздуха. Средняя температура воздуха была $7,1^{\circ} \mathrm{C}$, что выше среднемноголетней на $2,4{ }^{\circ} \mathrm{C}$. В апреле отмечалась умеренно теплая полгода, с незначительными периодическими осадками. Средняя температура воздуха была $11,6{ }^{\circ} \mathrm{C}$, что выше среднемноголетней на $1,4{ }^{\circ} \mathrm{C}$, максимальная $22,9{ }^{\circ} \mathrm{C}$, минимальная $4,6{ }^{\circ} \mathrm{C}$, относительная влажность воздуха $73 \%$.

Работу выполняли в соответствии с Методическими указаниями по селекции и семеноводству овощных культур [2] и Методическими указаниями по изучению и поддержанию мировой коллекции капусты [3]. У сортов определяли морфологическую однородность, скороспелость, длину вегетационного периода, урожайность, товарность кочана и биохимический состав продукции. Статистическую обработку экспериментальных данных проводили методом дисперсионного анализа [4].

\section{Результаты исследований}

Происхождение и ботаническое описание сорта Елизавета. Новый сорт капусты белокочанной озимой селекции ДСОСВиО Елизавета получен путем скрещивания $F_{1}$ Тахоку Михама × Офелия.

Растения средней высоты, положение внешних листьев - приподнятые, внешние листья - среднего размера, серо-зеленой окраски, края волнистые. Наружная и внутренняя кочерыги короткие. Форма кочана - конусовидная.

Особенности сортов белокочанной капусты представлены в таблице 1.

Хозяйственно-технологическая характеристика

В республике Дагестан капусту белокочанную возделывают в открытом грунте. Сорта капусты различаются по форме, размеру и плотности кочана, сроку потребления. Одно из главных хозяйственно-биологических свойств сорта Елизавета - скороспелость. В зависимости от условий года, особенно от срока наступления оптимальной для начала образования кочана температуры, скороспелость сортов капусты озимой меняется. При возделывании капусты белокочанной озимой в южном регионе следует точ-

Таблица 1. Характеристика сорта капусты белокочанной Елизавета в сравнении с сортом ДМУ (2017-2019 годы)

\begin{tabular}{|c|c|c|c|c|c|c|c|c|c|c|}
\hline Показатель & \multicolumn{5}{|c|}{ Сорт Елизавета } & \multicolumn{5}{|c|}{ Сорт ДМУ } \\
\hline Длина листа, см & 36 & 38 & 38 & 40 & 39 & 34 & 32 & 35 & 37 & 32 \\
\hline Ширина листа, см & 45 & 46 & 44 & 42 & 43 & 45 & 41 & 43 & 42 & 40 \\
\hline Кочерыга наружная, см & 12 & 13 & 12 & 16 & 16 & 12 & 12 & 14 & 13 & 12 \\
\hline Кочерыга внутренняя, см & 12 & 10 & 11 & 11 & 12 & 10 & 12 & 13 & 10 & 11 \\
\hline Длина кочана, см & 25 & 26 & 24 & 24 & 29 & 24 & 26 & 23 & 21 & 23 \\
\hline Ширина кочана, см & 18 & 19 & 18 & 20 & 19 & 17 & 18 & 16 & 19 & 18 \\
\hline Масса кочана, кг & 2,15 & 2,20 & 2,15 & 2,25 & 2,25 & 1,20 & 1,30 & 1,15 & 1,40 & 1,30 \\
\hline Транспортабельность & \multicolumn{5}{|c|}{ Средняя } & \multicolumn{5}{|c|}{ Средняя } \\
\hline Лежкость при хранении, сут. & \multicolumn{5}{|c|}{25} & \multicolumn{5}{|c|}{20} \\
\hline
\end{tabular}


но соблюдать сроки посева и высадки, чтобы растения не прошли стадию яровизации [5-11].

Исследования показали, что у сорта Елизавета при некотором запаздывании в сроках завязывания кочанов, созревание их наступает на 3-4 дня раньше контрольных сортов.

Число дней от массовых всходов до первой уборки у нового сорта меньше, чем у сортов-стандартов, а масса кочана выше, благодаря ее большей плотности (табл. 2).

Новый сорт Елизавета не уступает сортам ДМУ и Офелия по биохимической ценности свежей продукции, более того, превосходит сорт ДМУ по содержанию аскорбиновой кислоты.

Содержание нитратов в исследуемых сортах не превышает ПДК, а колеблется в предельно допустимых нормах от 640,0 до 646 мг/Кг (табл. 3).

Сорт Елизавета засухоустойчив, холодостоек, не стрелкуется. К болезням устойчив. Оптимальные сроки посева семян капусты белокочанной озимой в Дербентском районе - 1015 сентября. Посев - семенами в открытый грунт. Семена высевают в холодные рассадники. Почву под рассадник готовят заранее, с двукратным поливом, чтобы спровоцировать рост сорняков и последующей обработкой верхнего слоя мотыгой. Высадка рассады в открытый грунт на постоянное место с 1-20 ноября. Для высадки рассады почву вспахивают на 25-27 см, дискуют, выравнивают и нарезают борозды на 70 см.

Зимуют растения в открытом грунте. Самая суровая зима с морозом и снежным покровом 10-20 см за последнее десятилетие отмечена в 2011-2012 годах, когда температура воздуха достигала до минус $-17-18{ }^{\circ} \mathrm{C}$ и кратковременно до $-27^{\circ} \mathrm{C}$. Растения всех сортов в коллекции станции вымерзли, а у сорта Елизаветы пострадали единичные растения.

Уход за растениями в фазе рассады и за высаженными в поле растениями заключался в регулировании водного режима, прополке с рыхлением и подкормке минеральными удобрениями.

Сорт Елизавета отзывчив на все виды удобрений. После высадки, как только укоренится рассада, ее необходимо подкормить аммиачной селитрой 100 кг/га с последующим поливом, а вторую подкормку провести аммофосом 200 кг с последующей заделкой. После первой подкормки растения желательно прорыхлить, а после второй - провести окучивание рассады до первых нижних листьев. Желательно провести эту операцию до наступления холодов (до III декады ноября). Рано весной, как только появляется возможность выйти на поле, необходимое условие по уходу за растениями капусты - подкормить нитроаммофоской 200 кг/га, прополоть, провести окучивание и поливы. Также уход за растениями включает в себя борьбу с вредителями, в том числе опрыскивание всходов капусты (сентябрь-октябрь) от крестоцветных блошек, репной и капустной белянок, а также осенью и весной от капустной тли при заселении 5-10\% растений мелкими колониями тли. Осенью, в период роста и развития рассады, а, именно, в семядольном состоянии от крестоцветных блошек более эффективно действует препарат Суми-Альфа 0,2 л/га (рабочая жидкость 300 л/га), а весной БИ-580,5 л/га (рабочая жидкость 300400 л/га). Осенью и весной можно использовать препараты Алтер 0,1 л/га, Фастак 0,1 л/га, Кимикс 0,2-0,3 л/га (300-400 л/га рабочей жидкости) против указанных вредителей.

Многое зависит от качества посадки. Рассаду следует сажать достаточно глубоко, вертикально и плотно обжимать, чтобы при легком подергивании она не извлекалась из почвы. Влажность почвы при посадке поддерживается на уровне $70 \%$ ПВ. В зависимости от влажности почвы, за вегетацию проводят 3-5 поливов преимущественно в период завязывания кочанов.

В сухом и жарком климате озимая капуста развивается плохо, кочаны получаются мелкими. Наилучшая температура для ее роста $15-18^{\circ} \mathrm{C}$.

Производственная оценка показала, что сорт Елизавета отличается повышенной морозоустойчивостью, устойчива к растрескиванию кочанов при поливах, к цветушности (не более $1, \%)$, дает большой выход стандартной продукции.

Таблица 2. Результаты оценки сортов капусты белокочанной озимой в конкурсном сортоиспытании (2017-2019 годы)

\begin{tabular}{|c|c|c|c|c|c|c|c|c|}
\hline \multirow[b]{2}{*}{ Сорт } & \multirow[b]{2}{*}{$\begin{array}{c}\text { Доля } \\
\text { погибших, \% }\end{array}$} & \multicolumn{2}{|c|}{ Число дней от } & \multicolumn{2}{|c|}{ Урожай, т/га } & \multirow[b]{2}{*}{$\begin{array}{c}\text { Стандар- } \\
\text { тность } \\
\text { кочанов,\% }\end{array}$} & \multirow{2}{*}{$\begin{array}{c}\text { Стандар- } \\
\text { тность по } \\
\text { отношению } \\
\text { к контро- } \\
\text { лю, \% }\end{array}$} & \multirow[b]{2}{*}{$\begin{array}{c}\text { Средняя } \\
\text { масса } \\
\text { товарного } \\
\text { кочана кг }\end{array}$} \\
\hline & & $\begin{array}{c}\text { массовых } \\
\text { всходов до } \\
\text { созревания }\end{array}$ & $\begin{array}{c}\text { массовых } \\
\text { всходов } \\
\text { до первой } \\
\text { уборки }\end{array}$ & общий & товарный & & & \\
\hline ДМУ (к) * (стандарт) & 4 & 234 & 249 & 21,8 & 21,2 & 97,2 & 100 & 1,2 \\
\hline Офелия (контроль) & 3,2 & 233 & 248 & 22,0 & 21,7 & 98,6 & 102,3 & 1,6 \\
\hline Елизавета & 1,8 & 231 & 246 & 22,2 & 21,8 & 98,2 & 102,8 & 2,2 \\
\hline $\mathrm{HCP}_{05}$ & & & & & 1,6 & & & \\
\hline
\end{tabular}

Таблица 3. Характеристика качества кочанов у сортов капусты белокочанной (среднее за 2017-2019 годы)

\begin{tabular}{|c|c|c|c|c|c|c|c|}
\hline \multirow[b]{2}{*}{ Сорт } & \multicolumn{3}{|c|}{ Macca, кг } & \multirow[b]{2}{*}{$\begin{array}{c}\text { Плотность } \\
\text { кочана, балл. }\end{array}$} & \multicolumn{3}{|c|}{ Содержание } \\
\hline & общая & $\begin{array}{c}\text { кочана без } \\
\text { кочерыги }\end{array}$ & кочерыги & & $\begin{array}{c}\text { содержание } \\
\text { растворимого } \\
\text { сухого } \\
\text { вещества,\% }\end{array}$ & $\begin{array}{c}\text { содержание } \\
\text { витамина С, мг\% }\end{array}$ & нитраты мг/кг \\
\hline ДМУ (стандарт) & 1,62 & 1,2 & 0,42 & 3,5 & 6,02 & 16,0 & 640 \\
\hline Офелия & 2,08 & 1,6 & 0,48 & 3,9 & 5,20 & 18,2 & 646 \\
\hline Елизавета & 2,70 & 2,2 & 0,50 & 4,2 & 5,80 & 18,0 & 643 \\
\hline
\end{tabular}




\section{Выводы}

По результатам исследований, капуста белокочанная сорта Елизавета - перспективный скороспелый, высокоурожайный в условиях орошения, устойчивый к морозам сорт для возделывания в озимой культуре. Сорт обладает также высокой зимостойкостью и засухоустойчивостью. Относительно устойчив к цветушности и основным болезням капусты. Достоинство сорта - устойчивость кочанов капусты к растрескиванию.

Сорт Елизавета представляет интерес для возделывания в озимой культуре в субтропических районах. Рекомендуется для внедрения в производство не только в Дагестане, но и во всех южных регионах России. Сорт Елизавета будет передан в ГСИ в 2020 году.

\section{Библиографический список}

1.Костенко Г.А., Монахос Г.Ф. Новые гибриды капусты белокочанной позднего срока созревания для Нечерноземной зоны. Международная научно-практич. конференции «Капустные овощные культуры. Актуальные вопросы селекции и семеноводства. Современные технологии выращивания» Г. Краснодар 2010 г. Краснодар. 2012. С. 74-79

2.Методические указания по селекции капусты. сост.: Г.В. Боос, И.Е. Китаева. М.: ВНИИССОК. 1989. 82 с.

3.Методические указания по изучению и поддержанию мировой коллекции капусты. Сост.: Г.В. Боос, Т.И. Джохадзе, А.М Артемьева и др. Л. ВИР. 1988. 117 с.

4.Доспехов Б.А. Методика полевого опыта (с основами статистической обработки результатов исследований). М. Агропромиздат. $1985.416 \mathrm{c}$.

5.Чернышева Н.Н. Капуста. Монография. Барнаул: Изд. АГАУ 2007. 169 c.

6.Гаджимустапаева Е.Г. Скороспелость озимой капусты цветной (Brassica cauliflower Lizg.) в условиях Южного Дагестана. Научно-практ. журнал Проблемы развития АПК региона. № 2 (6). 2011. C. 7-10

7.Казахмедов Р.Э., Гаджимустапаева Е.Г., Пулатова К.Д. Влияние физиологически активных соединений на всхожесть семян старой репродукции растений видов родов Brassica. Проблемы развития АПК региона. 2014.№3. С. 44-46

8.Гаджимустапаева Е.Г., Пулатова К.Д. Сорта белокочанной капусты для юга России. Вестник российской сельскохозяйственной науки. 2015. №1. С. 40-42

9.Умарова З.Г., Пулатова К.Д., Балабегова Н.М. Результаты изучения капусты белокочанной на ДСОСВиО в 2013-2014 гг. Вестник социально педагогического института. № 2 (14). 2015. C. 1-6

10.Казахмедов Р.Э., Мамедова С.М. Коллекция сортов капусть белокочанной озимой селекции ДСОСВиО. Проблемы развития АПК региона. 2018. №4 (36). С. 57-62

11.Казахмедов Р.Э., Магомедова М.А. Особенности генеративного развития сортов капусты белокочанной озимой в условиях юг России и его гормональная регуляция. Вестник Российской сельскохозяйственной науки.2018. №4. С. 38-40

\section{References}

1.Kostenko G.A., Monahos G.F. New hybrids of cabbage of late ripening period for the non-Chernozem zone. International scientific practical conference - Cabbage of the vegetable crops. Current issues of selection and seed production. Modern technologies of cultivation. Krasnodar. 2010. Krasnodar. 2012. Pp. 74-79 (In Russ.). 2.Guidelines for cabbage selection/comp.: Boos G.V., Kitaeva I.E. Moscow: VNIISSOK.1989. 82 p. (In Russ.).

3. Guidelines for the study and maintenance of the world's cabbage collection. Comp.: G. V. Boos, T. I. Dzhokhadze, A. M. Artemyeva et al. VIR. 1988. 117 p. (In Russ.).

4.Dospekhov B.A. Method of field experience (with the basics of statistical processing of research results). Moscow: Agropromizdat, 1985. 416 p. (In Russ.).

5.Chernysheva N.N. Cabbage. Monograph. Barnaul. 2007. 169 p.

6.Gazhimustapaeva E.G. Precocity of winter cauliflower (Brassica cauliflower Lizg) in the conditions of southern Dagestan, in: Problems of agricultural development in the region. No. 2 (6). 2011. Pp. 7-10 (In Russ.).

7.Kazahmedov R. E., Hadzimustafa E. G., Pulatov K. D. Effect of physiologically active compounds on the germination of old reproduction of plants of species of the genera Brassica. Problems of agricultural development of the region. 2014. No. 3. Pp. 44-46 (In Russ.).

8.Gadzhimustapaeva E.G., Pulatova K.D. Varieties of white cabbage for the South of Russia. Bulletin of the Russian Agricultural Science. 2015. No. 1. Pp. 40-42 (In Russ.)

9.Umarova Z.G., Pulatova K.D., Balabegova N.M. Results of the study of white cabbage on DESVVG in 2013-2014. Bulletin of the socio-pedagogical Institute. No. 2 (14). 2015. Pp. 1-6 (In Russ.).

10.Kazahmedov R.E., Mammadov S.M. Collection of varieties of cabbage, winter breeding of DESVVG. Problems of agricultural development of the region. 2018. No. 4(36). Pp. 57-62 (In Russ.).

11.Kazahmedov R.E., Magomedova M.A. Peculiarities of generative development of varieties of cabbage winter in the South of Russia and its hormonal regulation. Bulletin of Russian agricultural science. 2018. No.4. Pp. 38-40 (In Russ.).

\section{Об авторах}

Казахмедов Рамидин Эфендиевич, доктор биол. наук, в.н.с., зам. директора по науке. Дагестанская селекционная опытная станции виноградарства и овощеводства - филиал Федерального государственного бюджетного учреждения «Северо-Кавказский федеральный научный центр садоводства, виноградарства, виноделии» (ДСОСВиО). E-mail: kre_05@mail.ru

Кафарова Нияра Мирзалиевна, н.с. лаборатории селекции, сортоизучения винограда, овощных и субтропических культур. дСОСВиО. E-mail:kafarova64@mail.ru

\section{Author details}

Kazahmedov R.E., Doctor of Sci. (Biol.), leading research fellow, deputy Director for science. Dagestan Selection and Experimental Station for Viticulture and Vegetable Growing (DSESVVG) - a branch of the Federal State Budgetary Institution North Caucasus Federal Scientific Centre of Horticulture, Viticulture, and Winemaking. E-mail: kre_05@mail.ru

Kafarova N.M., research fellow, laboratory of selection, varietal studies of grapes, vegetables and subtropical crops. DSESVVG. E-mail:kafarova64@mail.ru
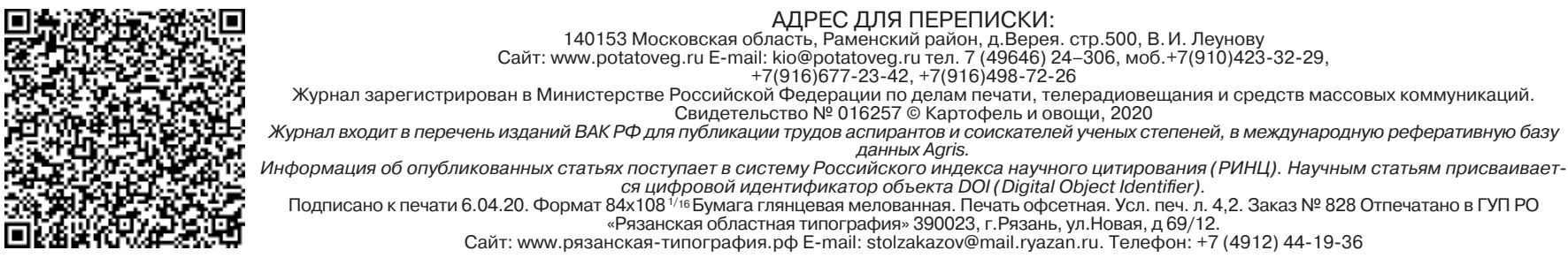